$\infty$

0

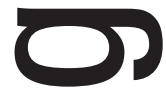

-

ת

1

$\longrightarrow$ 



\title{
DESIGUALDADES SÓCIO-ESPACIAIS, DEMOCRACIA E GESTÃO METROPOLITANA: ANÁLISE DO DESEMPENHO INSTITUCIONAL EM GOIÂNIA (1997-2007)
}

\author{
PARTNER-SPATIAL INEQUALITIES, DEMOCRACY AND MANAGEMENT METROPOLITAN: ANALYSIS \\ OF THE INSTITUTIONAL PERFORMANCE IN GOIÂNIA (1997-2007)
}

\author{
Adão Francisco de Oliveira - UNITINS \\ adaofrancisco@gmail.com \\ Eguimar Felício Chaveiro - IESA/UFG \\ eguimar@hotmail.com
}

\section{Resumo}

0 desenvolvimento urbano de Goiânia e a sua conseqüente formação metropolitana resultou na constituição de uma série de novos problemas sócio-territoriais. Destes, chama a atenção a irradiação das desigualdades, explícitas nesta nova "ordem" (ou caos?) pela descentralização dos investimentos imobiliários de luxo - tais como os condomínios para a classe média-alta - e pelos de mercado em geral. Com isto, os recantos da cidade passaram a reproduzir a relação isotopia-heterotopia, ou seja, as formas e condições da referência urbana e a sua diferença. Contudo, na diferença destaca-se a segregação sócio-espacial, tornando-se no principal desafio a ser superado pelo esforço metropolitano. Para tanto, a Constituição da República de 1988 muniu a institucionalidade com uma série de dispositivos que causam a descentralização administrativa e a democratização das decisões das políticas públicas. Um dos principais sentidos para isso é absorver a potencialidade das sócio-lógicas (Lefebvre, 1999) na resolução dos problemas e, conseqüentemente, dos conflitos sociais. Diante disso, este trabalho pretende responder como que as gestões municipais de Goiânia, entre os anos de 1997 e 2006, se utilizaram da poliarquia (Dahl, 1997), ou seja, da ampliação da condição democrática para resolverem os problemas advindos das desigualdades sócio-espaciais na cidade.

Palavras-chave: Goiânia; desigualdades socioespaciais; democracia; governança urbana

\section{Summary}

The urban development of Goiânia and its consequent formation metropolitan resulted in the constitution of a series of new partner-territorial problems. Of these, the irradiation of the inaqualities calls the attention, explicit in this new "order" (or chaos) for the decentralization of the real estate investments of luxury - such as the condominiums for the upper-middle class - and for the ones of market in general. With this, the hiddings place of the city had started to reproduce the isotopy-heterotopy relation, that is, the forms and conditions of the urban reference and its difference. However, in the difference it is distinguished partner-spatial segregation, becoming in the main challenge to be surpassed by the metropolitan effort. For in such a way, the Constitution of the Republic of 1988 armed the institucionalidade with a series of devices that cause the administrative decentralization and the democratization of the decisions of the public policy. One of the main ones felt for this is to absorb the potentiality of the sociological ones (Lefebvre, 1999) in the resolution of the problems and, consequently, the social conflicts. Ahead of this, this work intends to answer as that the municipal managements of Goiânia, enter the years of 1997 and 2006, if they had used of the poliarchy (Dahl, 1997), that is, of the magnifying of the democratic condition to decide the happened problems of the partner-spatials inaqualities in the city.

Key-words: Goiânia; partner-spatial inaqualities; democracy; urban governance

\begin{tabular}{|l|c|c|c|c|c|c|}
\hline Boletim Goiano de Geografia & Goiânia - Goiás - Brasil & v. 28 & n. 2 & p. 187-202 & jul. / dez. & 2008 \\
\hline
\end{tabular}





\section{Introdução: a experiência metropolitana de Goiânia}

A experiência urbana de Goiânia nos leva a compreendê-la como uma metrópole precoce. Idealizada e concretamente iniciada no limiar dos anos de 1930, Goiânia encerrou o século XX na condição institucional de metrópole, tendo atingido em 2005, segundo estimativas do IBGE, aproximadamente 1,2 milhão de habitantes, sendo que sua região metropolitana, neste mesmo ano, constituída por mais 11 municípios $^{1}$, alcançou 1.934 .771 habitantes.

Construída numa localização estratégica no Estado de Goiás para alojar não só o centro do poder político como também do desenvolvimento econômico, Goiânia satisfez a uma dupla dimensão de interesses. A primeira é a idealizada por Pedro Ludovico Teixeira na representação política dos produtores agropecuários do sul/sudoeste do Estado. Nesta, a nova capital do Estado estaria topicamente distante da influência das velhas oligarquias goianas - influência esta exercida a partir da cidade de Goiás -, sob liderança dos Caiado e atenderia com mais precisão a demanda por infra-estrutura e serviços públicos das regiões sul e sudoeste do Estado, articuladas à economia de mercado dirigida pelo centro-sul do país (CAMPOS, 2002; CHAUL, 1997, 2000; OLIVEIRA, 2002b). A segunda dimensão é aquela dirigida por Getúlio Vargas, que via Goiânia como um entreposto para a concretização do projeto de segurança nacional e, ao mesmo tempo, um trampolim para a articulação do centro-norte amazônico à economia de mercado, como pretendiam os investidores do capital (BERNARDES, 1998; CHAUL, 2000; OLIVEIRA, id.). Goiânia seria, nesta perspectiva, um instrumento fundamental da política da "Marcha para o Oeste".

Assim, entre as décadas de 1930 e 1960 a capital goiana foi o palco de decisões políticas que, por um lado, viabilizaram o avanço da fronteira econômica para fora de seu território, rumo ao norte do país - integrando todo o território goiano, no geral, à rede de mercado capitalista e potencializando seu “papel” na divisão regional do trabalho (BORGES, 2000). Por outro lado, para que Goiânia suportasse o peso de sua representação, tais decisões a produziram razoavelmente na sua dimensão pública para, a partir de 1950, permitirem a privatização das iniciativas de seu desenvolvimento. A este respeito é interessante o que dizem alguns estudiosos sobre a cidade, ao conceituarem o período. Para Everaldo Pastore (1984) o período significou “a privatização do parcelamento do solo em Goiânia”; Elza G. Chaves (1985) o compreende como sendo de "privatização do espaço e conflitos urbanos"; 
Sérgio Moraes o identifica como sendo a "fase de ampliação do espaço" de Goiânia; e Welton F. de Souza (1996) o compreendeu como o período em que

os administradores e políticos, de um modo geral, [se esqueceram] de gerenciar a cidade, conforme planejamentos e leis. Os locais de moradia passaram a se dispersar por áreas distantes, sem serviços públicos e benfeitorias urbanas. Os vazios demográficos de Goiânia, causados pela retenção de terrenos particulares sem utilização nas áreas urbanizadas, favoreceram os interesses especulativos, têm surtido graves problemas a toda sociedade e excluído os migrantes provenientes do êxodo rural. (apud OLIVEIRA, 2005).

Desta forma, a gestão pública sobre a capital do Estado de Goiás aproximava a lógica de desenvolvimento da cidade à nova fase do desenvolvimentismo nacional, que garantiu privilégios à iniciativa privada nas ações sobre os territórios, resumindo-se à montagem de infra-estrutura básica e de serviços e a mediar os interesses capitalistas. O impacto dessa condição política sobre Goiânia foi estrondoso, haja vista que sobre esta cidade recaia uma intensa procura por moradia e alternativa de sobrevivência de famílias retirantes da zona rural e de pequenas cidades sem grandes perspectivas, tanto de Goiás quanto de outros Estados, principalmente do Nordeste (em particular do Maranhão e da Bahia) e de Minas Gerais. Este movimento foi reforçado a partir de meados dos anos de 1950, com a criação de Brasília, pois com esta se formou um curto eixo de desenvolvimento e de possibilidades entre as duas cidades que se tornou um grande pólo de atração humana para a região. O resultado de tudo isso foi um intenso crescimento demográfico de Goiânia, de acordo com os seguintes índices: de 1950 a 1960, 187,5\%; de 1960 a 1970, 153,9\%; e de 1970 a 1980, 109,7\%. Ou seja, Goiânia saltou de uma população de 53.389 habitantes em 1950 para 817.343 habitantes em 1980 (SOUZA, 1996, p. 38, apud OLIVEIRA, 2002b, p. 71).

Neste contexto, o desenvolvimento urbano de Goiânia passou a ser visto como um problema, sendo que em 1980 ele coincidiu com aquilo que Lefebvre (1999b, p. 27) denominou de a explosão-implosão da cidade: "concentração urbana, êxodo rural, extensão do tecido urbano, subordinação completa do agrário ao urbano”. Caracterizava-se, assim, o fenômeno urbano em Goiânia, com a aproximação de sua realidade àquilo que este autor chamou de "zona crítica", o 100\% urbano. A este turno, as contradições advindas das formas desiguais de ocupação do solo na cidade que se sucederam a partir de 1950 transformaram-se em movimentos sociais e culminaram em 
conflitos pela posse da terra. Isto porque pela lógica do valor diferencial do solo - dominado pelos interesses de mercado - produziu-se uma cidade central, referencial, formal, da bela estética, isotópica, ao mesmo tempo em que se produziu também a sua diferença, que vai da estrutura e estatura dos prédios, da largura e da limpeza das ruas, do tipo de movimento que se verifica no sistema viário, ao seu radical contrário: o informe e a informalidade. É a heterotopia urbana, que através dos conflitos sociais, revela a sua dimensão paradigmática, ao explicitar as oposições e diferenças.

Segundo Oliviera (2002a, p. 68),

A disposição espacial das pessoas na cidade reflete a condição de classe, de forma que os lugares ordenam-se representando em forma e conteúdo a situação sócio-econômica dos grupos que os ocupam. Este fator completa a gama de situações que podem resultar em conflitos sociais: produção material - desigualdades no trabalho, conflito entre capital e trabalho, mais-valia; formulação intelectual-ideológica - diferenças político-partidárias, fundamentalismo religioso etc.; ocupação espacial desigual - expressão de marginalidade, confinamento, destituição de infra-estrutura e serviços públicos.

Nestas dimensões, Goiânia viu não só seu sítio urbano maior, como também sua diversidade, pois passou a agregar "uma variabilidade de possibilidades de trabalho, de níveis de consumo, de papéis sociais e de proveniência de pessoas" (COSTA, 2005, p. 80). A sua condição e forma cosmopolitas se associaram à dinâmica metropolitana que a cidade passou a ter com a explosão-implosão do fenômeno urbano. A dualidade de contraste radical entre centro e periferia, a existência - de simbolismo violento - de grandes vazios urbanos com lógica especulativa a separar ambos espaços, a saturação visual, o congestionamento populacional das áreas centrais, a violência física empreendida pelo Estado no controle dos usos segregados da cidade, tudo isso forçou a procura pelos municípios vizinhos a Goiânia como novos espaços habitacionais. Para continuar usando Goiânia, os novos "chegantes" habitavam a vizinhança urbana, reproduzindo a mesma lógica perversa do mercado da terra nos municípios vizinhos, provocando uma conurbação perceptível já no limiar dos anos de 1990 e redimensionando os desafios do embate político e da gestão urbana.

Tal fenômeno se reforçou mediante o quadro nacional de crise fiscal e financeira que caracterizou a década de 1980 como sendo a "década perdida" da economia. Em função da fixação de novos padrões de acumulação de capital pelos países do capitalismo central (particularmente pelos EUA e pela Inglaterra), uma política de ajustes neoliberais foi impetrada, o que le- 
vou a um reordenamento das ações das agências financeiras internacionais, tais como o Banco Mundial e o FMI, e dos Estados Nacionais.

No caso das primeiras, houve um contingenciamento de recursos a serem investidos em países "subdesenvolvidos" ${ }^{2}$ para que se pudesse dar suporte às transformações econômicas e políticas dos países centrais. Isto fatalmente provocou uma crise financeira, que foi seguida por uma outra, de caráter fiscal, haja vista que a recomendação que foi feita aos Estados das nações emergentes era de que flexibilizassem na cobrança de impostos e taxas dos grandes investidores capitalistas. Isto porque uma vez que os Estados ficariam destituídos dos recursos oriundos de empréstimos das agências financeiras, não poderiam subvencionar com recursos públicos, como era de costume, as dívidas de tais investidores. Assim, para atenuar a crise macroeconômica, provocou-se um ajuste fiscal que levou ao sacrifício as políticas sociais e os grandes centros urbanos.

No caso do Brasil, tal medida tornou contundente a fragmentação existente entre as classes sociais, manifesta, principalmente, nos espaços metropolitanos. Isto criou cenários de insustentabilidade, justificados pelas elites econômicas - que buscaram se eximir de sua plena responsabilidade sobre a questão - como uma "desordem [emanada] dos espaços das camadas populares e de suas práticas” (RIBEIRO, 2004, p. 17). Entre a década de 1980 e o período atual o que se percebe é um aprofundamento da crise, haja vista que o principal responsável em encontrar resposta para o problema, o Estado, esfacelou-se mediante os ajustes de caráter neoliberais. São os reflexos da globalização, assim compreendidos por Ribeiro (id., p. 18):

Vivemos hoje um momento de transição histórica e intelectual sob o impacto da crise do modelo desenvolvimentista e da nossa inserção no novo modelo de produtividade difundido pela globalização. O grande e constante contingente de pobres, de desempregados, de empregados precários, de moradias em favelas e cortiços, a exacerbação da violência, tudo isto vem alimentando incertezas acerca do futuro das grandes cidades brasileiras com o aprofundamento da globalização e da reestruturação produtiva.

Por sua vez, Chaveiro (2005, p. 172-173) chama a atenção para tais transformações próprias da sociedade globalizada destacando a estranheza que fazem operar nos circuitos locais de realização da vida:

Autores como Santos (1996), Melucci (2001) e Pelbart (2000) centram a sua análise espacial referendando-o como um espaço complexo. A unicidade do mundo conformando uma territorialidade globalitária, engravidou o espaço de uma enormidade de variáveis. Essas variáveis provenientes da 
tradição convergindo com modernas, urbanas, tecnológicas, informacionais, científicas, imagéticas, de capitais financeiros, migratórias, pela via da circulação criam uma complexidade. Essa complexidade se redunda em fluidez, escapatórias, conflitos, desigualdades, violências, criminalidades e aberrações psíquicas. O fato é que o espaço contemporâneo diferente do espaço da tradição é penetrado por variáveis estranhas à história local, à cultura local e às ações locais.

Assim, o que está posto é um contexto de profunda crise das metrópoles - particularmente as brasileiras - em função da ação homogeneizante do mercado globalizado, da cisão e da fragmentação entre as classes que coabitam a cidade, da concentração polarizada de riquezas nos núcleos metropolitanos e, nestes núcleos, nos condomínios fechados que dividem muro com periferias proletárias, da ingovernabilidade que se apresenta não só pelo esfacelamento do Estado como também pela sócio-lógica neoliberal que despolitiza tais questões. Goiânia, assim como as grandes metrópoles brasileiras, experimenta este problema, esta "zona crítica", de forma extremamente fragilizada na sua representação política.

\section{A luta pelo direito à cidade e a ampliação democrática}

Ao longo da década de 1980, quando o fenômeno urbano se revelou a Goiânia, a reivindicação da cidade feita pelas camadas sociais segregadas pelo autoritarismo do capital - com destaque aqui ao capital imobiliário - as colocou no espaço público. Movimentos sociais foram responsáveis por uma nova ordem da cidade, a ordem dual: de um lado, a cidade planejada pelo Estado - na institucionalidade do poder público municipal -, expressante de uma lógica de ordenação excludente ${ }^{3}$, na qual as camadas populares se viam restritas ao acesso da urbanidade. De outro, a cidade resultante da ação cotidiana destas mesmas camadas, que na busca de garantia de sua sobrevivência, reinventaram a cidade na produção de seus espaços de referência, contraditórios com a centralidade; produziram uma heterotopia conformada à feição das desigualdades sócio-espaciais. Porém, a produziram na polifonia de suas ações coletivas, rompendo com a mordaça imposta pelo regime militar. As camadas populares se fizeram sujeitos da cidade, da polis, buscando definir uma situação de cidadania.

Esta dinâmica se repetiu na sociedade brasileira como um todo, tendo validade principalmente nas grandes cidades. O resultado desta relação 
social contraditória a produzir territorialidades se deu na construção de um novo marco regulatório para o país, expresso na Constituição de 1988. A essência desta reproduz o dilema / dialogia da sociedade, instituindo ao mesmo tempo e em condições de igualdade direitos econômicos - fundamentais para a garantia da propriedade privada - e direitos sociais - fundamentais à conquista e manutenção da cidadania. Contudo, o mais importante sobre a sua elaboração é a institucionalização de condições democráticas, abrindo possibilidades para que a população de um modo geral, em particular as camadas populares, possa participar da formulação e da deliberação de políticas públicas e do controle sobre as ações do Estado. Garantidos direitos, a disputa pela hegemonia social foi reforçada, no caso das elites econômicas e políticas do país, pelo projeto de "sociedade de massas" (HABERMAS, 1984, 1987), em que o domínio sobre o campo ideológico tem como principal recurso o uso das mídias.

O que isso tudo tem a ver com o problema das metrópoles brasileiras, particularmente a goianiense? Se por um lado a população brasileira - organizada em movimentos sociais, sindicais e entidades de classe - forçou a elaboração de uma constituição que garantiu direitos e ampliou legalmente a condição democrática, por outro a sua homologação coincidiu com o momento de maior força e imposição do projeto capitalista central de ajustes neoliberais. Assim, o convencimento ideológico pelo uso das mídias foi fundamental, ao longo da década de 1990, para garantir às elites brasileiras reformas constitucionais regulamentando primeiramente o direito econômico e adequando o Estado às novas exigências de mercado - um Estado mínimo.

Nestes termos, por mais que as metrópoles brasileiras já se encontrassem críticas, as novas ações de mercado - agora com poderes quase que ilimitados - reforçaram a crise, destituindo o Estado - enquanto sociedade política e organização burocrática de planejamento - das possibilidades de soluções estruturais para o problema. O seu papel de mediador entre as classes passou a contar com intervenções pontuais / focais sobre as desigualdades agravadas, ao passo que, pela lógica imposta pelo domínio midiático, passou a potencializar os investimentos capitalistas em ações de privatização dos recursos públicos.

Para as cidades, e não é repetitivo destacar as metrópoles, o problema se impôs com uma dimensão ampliada. Isto porque uma das "importantes" ações oriundas da nova Constituição da República foi a descentralização administrativa, repassando aos municípios responsabilidades antes perten- 
centes à União. Porém, num contexto de crise fiscal e financeira e de esfacelamento do poder do Estado, os municípios passaram a viver um verdadeiro vazio epistemológico quanto às formas de sua gestão. Que ações tomar para conter a crise urbana derivada, fundamentalmente, da explicitação da segregação sócio-espacial? De que recursos dispor para empreender as ações? Como conter as insatisfações sociais e o escopo da violência urbana? São algumas das questões que se impuseram neste novo quadro.

Uma das possibilidades dadas para tanto consiste no aproveitamento e na absorção das forças locais para a construção coletiva das respostas, utilizando-se dos dispositivos democratizantes instituídos pela Constituição da República. Porém, isto implica, em certa medida, em empoderar as camadas populares (principais objetos do desconcerto segregatício) e, conseqüentemente, em construir novas matizes para a cultura cívica e política. Isto consiste em permitir a tais camadas sociais a manifestação de sua sócio-lógica (LEFEBVRE, 1999b), a apresentação de sua territorialidade (HAESBAERT, 2004), a demonstração de sua significação (SANTOS, 2004). Verifica-se aí a instalação de um dilema na gestão das metrópoles, pois na perspectiva elitista liberal-conservadora a

Cidadania produtiva requer a supremacia do conhecimento concebido por meio do discurso competente, e assim a despolitização das questões cotejadas pelos clamores de civilidade e democracia, aquelas dos próprios movimentos reivindicativos dos elementos da urbanidade - as diversas formas da riqueza. Enfim, o conhecimento da sociedade brasileira, considerando-se a centralidade material - e simbólica - das metrópoles, é continuamente arrastado par o sofisma da incompatibilidade entre a construção democrática - efetivamente participativa, da concepção à decisão - e a eficácia na e da sociedade. Fica então o Estado como o único escopo legítimo para a fundação e a restauração da ordem social; deve ser um demiurgo a redimir a sociedade. (ALVES, 2006, p. 74).

Neste trabalho, o que se pretende é verificar que respostas a estes problemas foram buscadas e construídos na gestão da metrópole goianiense.

\section{Democracia, condição democrática e poliarquia}

A democracia é, sem sombra dúvida, um conceito difícil de se definir, uma vez que a experiência real apresenta uma variação muito grande de condições democráticas. A sua instituição se dá pelo marco regulatório de um Estado-nação, mas as suas formas podem variar de acordo como os seus 
usos territorializados dentro deste Estado. De acordo com Dahl (1997, p. 25), se compreende a democracia a partir do "pressuposto de que uma característica-chave [sua] é a contínua responsividade do governo às preferências dos seus cidadãos, considerados como politicamente iguais”. Assim, aos cidadãos devem ser garantidas as seguintes oportunidades na sua plenitude:

1. De formular suas preferências;

2. De expressar suas preferências a seus concidadãos e ao governo através da ação individual e coletiva;

3. De ter suas preferências igualmente consideradas na conduta do governo, ou seja, consideradas sem discriminação decorrente do conteúdo ou da fonte da preferência. (SANTOS JÚNIOR, 2001, p. 69).

A forma como os governos geram estas condições relaciona-se com os regimes democráticos, existentes numa ampla variedade de situações. Por isso, Dahl (op. cit., p. 31) prefere designar as experiências reais dos sistemas políticos de poliarquia. Por esta, se entende "um regime fortemente inclusivo e amplamente aberto à contestação política". Por regime aberto se entende a liberalização da competição política por ato institucional, bem como o reconhecimento da igualdade de direitos e a aceitação dos resultados da competição. Já por regime inclusivo (ou inclusividade), se entende a participação social em eleições e em cargos públicos eletivos, bem como na sua organização social, também com garantia de direitos. Compreende-se melhor a poliarquia na contraposição de regimes contrários, tais como: 1) a hegemonia fechada; 2) a hegemonia aberta; e 3) a oligarquia competitiva.

A articulação deste conceito com o de esfera pública (HABERMAS, 1984) nos permite uma boa compreensão das experiências dos conselhos gestores no Brasil e a sua importância no cenário local de Goiânia. Entende-se por esfera pública a arena de encontro entre a sociedade civil (organizada nos espaços públicos - ONG’s, associações, movimentos sociais e sindicais etc.) e o Estado para a formulação, deliberação e o monitoramento das políticas públicas. Naturalmente, a esfera pública é uma arena de conflitos, haja vista que nela se pretende os olhares sobre determinadas situações e territórios na tentativa de um pacto social. Como ela não é nem espaço público e nem Estado, alguns autores a compreendem como uma coisa híbrida, mas de importância fundamental (SANTOS, 1998 apud SANTOS JÚNIOR, op. cit.). 


\section{Desempenho institucional}

Como recurso metodológico, pretende-se neste trabalho avaliar as experiências democráticas em sua conexão com o desempenho institucional das gestões. Para tanto, a pesquisa desenvolvida por Putnam (2002) na Itália durante 19 anos é a nossa principal referência. Segundo este autor, o desempenho institucional é um fenômeno complexo e de difícil avaliação, pois as decisões governamentais que caracterizam as gestões envolvem fatores distintos, tais como os de ordem institucional, sócio-econômicos e sócio-culturais. Porém, uma gestão positiva é aquela que consegue articular três elementos: sensibilidade - capacidade de percepção do gestor e da gestão para as demandas sociais, eficiência - precisa organização dos processos e recursos para apresentação da resposta às demandas, e eficácia - resolutividade da política adotada.

A positividade destes elementos se verifica nos seguintes indicadores do desempenho institucional:

a) continuidade administrativa (estabilidade do gabinete, presteza orçamentária etc.);

b) deliberações sobre as políticas (legislação reformadora e inovação legislativa);

c) implementação das políticas (investimento nas políticas sociais e econômicas).

Este referencial teórico e metodológico orienta para uma investigação que localiza as seguintes fontes:

i. conselhos gestores (leis de criação, datas de criação, períodos de atividade/inatividade, participação de gênero e cor, quantidade de reuniões mensais, organização interna, formas de escolha dos representantes etc.);

ii. orçamento participativo (lei de criação, expansão dos direitos de participação dos cidadãos, formas de realização na cidade e quantidade de edições em um ano, quantidade de participantes por edição em relação à população distrital/regional, percentual do orçamento geral decidido nas edições, realização/implementação das decisões etc.);

iii. Conferência da cidade (formas de escolha dos delegados, preparação anterior dos delegados para participação nas discussões e na plenária, disposição de informações, formas de tratamento para as camadas e interesses sociais distintos, deliberações perante os instrumentos normativos etc.); 
iv. Agenda Goiânia (estatuto do evento, expansão dos direitos de participação dos cidadãos, formas de realização na cidade e quantidade de edições em um ano, quantidade de participantes por edição em relação à população distrital/regional, condução das discussões, relatoria dos entendimentos, realização/implementação dos entendimentos etc.).

\section{Desempenho institucional em Goiânia}

Na avaliação que fazemos das experiências democráticas nas gestões de Goiânia, localizamos as seguintes situações:

i) A resposta a este problema varia de governo para governo e é apresentada de acordo com a matriz político-ideológica do grupo que o exerce bem como de sua vinculação e compromisso com as classes sociais em disputa;

ii) Como a poliarquia é definida pelo concerto de condições democráticas mobilizadas, temos as seguintes situações:

a. Governo Nion Albernaz - PSDB (1997 a 2000). Não se criou nenhum arranjo institucional para garantir a participação social na gestão urbana, limitando-se a homologar a constituição de conselhos gestores - enquanto esfera pública (HABERMAS, 1984) -, principalmente os exigidos por legislação federal. Com isso, houve um acirramento das contradições sociais e um nítido privilégio aos agentes do mercado, principalmente do imobiliário. Portanto, foi um governo conservador, de BAIXO nível poliárquico mas de alto controle de situação;

b. Governo Pedro Wilson - PT (2001 a 2004). Desenvolveu como arranjo institucional o Orçamento Participativo - OP, e a Conferência da Cidade, abrindo possibilidade de um amplo debate social sobre a normatização, usos e intenções sobre a cidade e validando a decisão popular. Porém, descentralizou as decisões administrativas de modo a perder a integração das ações e, conseqüentemente, sua efetividade. Foi um governo progressista, de ALTO nível poliárquico mas de baixo controle de situação;

c. Governo Íris Rezende - PMDB (2005 a 2006). Desenvolveu, juntamente com a principal empresa privada de comunicação do Estado de Goiás - a Organização Jaime Câmara - e com a Uni- 
versidade Católica de Goiás - UCG, o “Agenda Goiânia” como arranjo institucional. Por ele, se discutiu a cidade em suas regiões, onde se ouviu o saber técnico, o saber científico e o saber popular no debate. Porém, é um instrumento esvaziado de poder, haja vista que por ele a população não decide, não delibera ações a partir de suas intenções. Estas ficam contidas pela Prefeitura, sendo que a decisão final é sempre do próprio prefeito. Portanto, é um governo populista, de MÉDIO nível poliárquico e de alto controle de situação;

iii) Como conseqüência das ações desses governos, é possível se traçar mapas de Goiânia apresentando ao longo deste período a migração sócio-espacial do empoderamento da sociedade civil, através da incidência das políticas públicas sobre o território e da redefinição de seus usos.

\section{Notas de encerramento}

Este trabalho implicou num exercício de aproximação que tentou demonstrar a íntima relação entre a questão urbana e a questão política. A primeira centrada nas contradições que demarcam o espaço segregado da metrópole atual, e a segunda focada na mobilização coletiva em torno das decisões sobre o futuro da cidade.

A pergunta fundamental, e que o prosseguimento dessa reflexão tentará responder é: na reunião de organizações coletivas em Goiânia os espaços institucionalizados estão se constituindo em um campo de atuação política fundamental para o futuro da cidade (urbano)? E mais: de que tipo são essas organizações coletivas e qual o sentido vetorial das decisões deliberadas?

A construção de um novo modelo de sociedade, ou seja, de cidade que se quer, passível de ser alcançada dentro dos marcos da institucionalidade, só será possível se houver o envolvimento efetivo do povo em processos de participação a partir do seu lócus de referência - a rua, o bairro, a região, o trabalho etc. Isto implica em dizer que, de onde quer que as pessoas estejam, uma sociedade pautada num modelo democrático que pretenda a sustentabilidade dentro de um contexto de desenvolvimento integrado, é fundamental a sua organização e participação nos processos institucionais decisórios.

Isto significa que a ampla participação popular faz com que a cultura política de gestão e de intervenção na cidade vai sendo transformada, na 
medida em que a apropriação da cidade vai se confirmando num processo contínuo de democratização dos espaços públicos. Não obstante, o exercício permanente de cidadania se erige frente à liberdade e à crítica de escolhas e decisões em espaços públicos.

Contudo, as experiências de gestão da Goiânia, principalmente a partir da década de 1990, do ponto de vista político-social, não possibilitou grandes avanços para a implantação de mecanismos estáveis de descentralização decisória do espaço urbano, mesmo nas administrações que neste período se apoiaram nos movimentos sociais de recorte popular. Instrumentos utilizados como Orçamento Participativo, Conferência das Cidades e Agenda Goiânia não conseguiram abrir espaço efetivo de participação que possibilitasse a criação de um novo centro de poder, com capacidade de intervenção, em consonância com os respectivos executivos do período, na perspectiva de dar uma feição mais democrática na gestão dos problemas urbanos.

1 A Região Metropolitana de Goiânia - RMG, foi criada em 1999 pela Lei Complementar n ${ }^{\circ}$ 27, que instituiu como finalidade "integrar a organização, o planejamento e a execução de funções públicas de interesse comum dos municípios dela integrantes” (cf. art. $2^{\circ}$ ). Faziam parte dela 11 municípios, sendo eles: Abadia de Goiás, Aparecida de Goiânia, Aragoiânia, Goianápolis, Goiânia, Goianira, Hidrolândia, Nerópolis, Santo Antônio de Goiás, Senador Canedo e Trindade. Porém, a partir de 2004, com a Lei Complementar $\mathrm{n}^{\circ} 049$, foi acrescentado a ela o município de Bela Vista de Goiás.

2 Esta expressão preconceituosa referia-se ao conjunto de países que não haviam atingido o mesmo padrão de desenvolvimento econômico e tecnológico que os países europeus, os EUA e o Japão. Na sua formulação, ignorava-se o fato de que tal desigualdade entre as nações era resultante mesmo da divisão internacional do trabalho, de tal modo que para os países do capitalismo de ponto esse quadro era muito importante. Porém, para mitigar o impacto ideológico da expressão, formulou-se no âmbito do Banco Mundial e do FMI um novo conceito, o de "países emergentes".

3 A respeito do planejamento urbano, em especial do planejamento de Goiânia, é interessante o que dizem alguns autores. Moysés (2004) produziu a tese de que o planejamento de Goiânia não contemplou a realidade metropolitana, marcada pela dimensão de sua desigualdade sócio-espacial e pobreza institucional. Portanto ela consiste numa metrópole não planejada. Já Moraes (2006) define o conjunto das desigualdades sócio-espaciais de cidades como Goiânia, Palmas e Brasília como pertinentes a uma segregação planejada. Oliveira e Moysés (2005) preferiram definir o quadro destas contradições como sendo reflexo de um planejamento excludente, haja vista que a ação do Estado, ao planejar o avanço das atividades de mercado, sedimenta as desigualdades dela resultantes. 


\section{Referências}

ALVES, William R. Reconhecendo metrópoles: território e sociedade (notas de um debate). In: SILVA, Catia A. da; FREIRE, Désirée G.; OLIVEIRA, Floriano J. G. de (orgs.) (2006). Metrópole: governo, sociedade e território. Rio de Janeiro: DP\&A, coleção "Espaços do desenvolvimento". 2006 .

BERNARDES, Genilda D. Goiânia, cidade planejada / cidade vivida: discurso e cultura da modernidade. Brasília, UnB - tese de doutorado em Sociologia. 1998.

BORGES, Barsanufo G. A economia goiana na divisão regional do trabalho (1930-1960). In: SILVA, Luiz S. D. da (org.). (2000). Relações cidade-campo: fronteiras. Goiânia: Editora da UFG. 2000.

Brasil.

CHAUL, Nasr N. F. (1997). Caminhos de Goiás: da construção da decadência aos limites da modernidade. Goiânia: Editora da UFG, 1997

Marchas para o oeste. In: SILVA, Luiz S. D. da (org.). (2000). Relações cidadecampo: fronteiras. Goiânia: Editora da UFG. 2000.

CHAVEIRO, Eguimar F. Traços, linhas e matrizes para a compreensão de um Goiás profundo. In: CHAVEIRO, Eguimar F (org.). A captura do território goiano e a sua múltipla dimensão socioespacial. Goiânia: Gráfica e Editora Modelo. 2005.

COSTA, Benhur P. da. As relações entre os conceitos de território, identidade e cultura no espaço urbano: por uma abordagem microgeográfica. In: ROSENDAHL, Zeny; CORREAA, Roberto L. Geografia: temas sobre cultura e espaço. Rio de Janeiro: Editora da UERJ. 2005.

DAHL, Robert. Análise política moderna. 2a edição. Brasília: Editora da UnB. 1987.

Um prefácio à teoria democrática. Rio de Janeiro: Jorge Zahar. 1989.

A poliarquia: participação e oposição. São Paulo: Editora da USP. 1997.

HABERMAS, Jürgen. Mudança estrutural da esfera pública. Rio de Janeiro: Tempo Brasileiro. 1984.

$\mathrm{n}^{\mathrm{o}} 36.1995$.

Três modelos normativos de democracia. In: Lua nova. São Paulo, CEDEC, Brasileiro, $2^{\circ}$ v. 1997

Direito e democracia: entre a factividade e a validade. Rio de Janeiro: Tempo

HAESBAERT, Rogério. O mito da desterritorialização. São Paulo: Bertrand Brasil. 2004.

LEFEBVRE, Henri. O direito à cidade. São Paulo: Editora Moraes. 1991.

A cidade do capital. Rio de Janeiro: DP\&A. 1999a.

A revolução urbana. Belo Horizonte: Editora da UFMG. 1999b.

OLIVEIRA, Adão F. A produção social do espaço. In: Cultura e liberdade. Goiânia, NUPAC, ano $2, \mathrm{n}^{\circ} 2.2002 \mathrm{a}$. 
Do "pântano" ao jardim, uma nova esperança: a produção social do espaço em Goiânia. Goiânia, UFG, dissertação de mestrado em Sociologia. 2002b.

A reprodução do espaço urbano de Goiânia: uma cidade para o capital. In: MOYSÉS, Aristides (org.). Cidade, segregação urbana e planejamento. Goiânia: Editora da UCG. 2005.

Goiânia heterotópica: a integração excludente. In: OLIVEIRA, Adão F.; NASCIMENTO, Claudemiro G. do (orgs.). Cidades sustentáveis: políticas públicas para o desenvolvimento. Goiânia: Editora da UCG. 2006.

OLIVEIRA, Adão F.; MOYSÉS, Aristides. Segregação e planejamento excludente: cidade informe e degradação ambiental em Goiânia. In: MOYSÉS, Aristides (org.). Cidade, segregação urbana e planejamento. Goiânia: Editora da UCG. 2005

OLIVEIRA, Adão F.; NASCIMENTO, Claudemiro G. do (orgs.). Cidades sustentáveis: políticas públicas para o desenvolvimento. Goiânia: Editora da UCG. 2006.

PUTNAM, Robert D. Comunidade e democracia: a experiência da Itália moderna. $3^{\mathrm{a}}$ edição. Rio de Janeiro: FGV. 2002.

RIBEIRO, Luiz C. de Q. (org.) Metrópoles: entre a coesão e a fragmentação, a cooperação e o conflito. São Paulo: Fundação Perseu Abramo; Rio de Janeiro: FASE. 2004.

SANTOS, Milton. Metamorfoses do espaço habitado: fundamentos teóricos e metodológicos da Geografia. São Paulo: Hucitec. 1994.

Pensando o espaço do homem. $5^{\text {a }}$ edição. São Paulo: Editora da USP. 2004.

SANTOS JÚNIOR, Orlando A. dos. Democracia e governo local: dilemas da reforma municipal no Brasil. Rio de Janeiro: Revan / FASE. 2001.

SANTOS JÚNIOR, Orlando A. dos et. all. Políticas públicas e gestão local: programa interdisciplinar de capacitação de conselheiros municipais. Rio de Janeiro: FASE. 2003.

SILVA, Catia A. da; FREIRE, Désirée G.; OLIVEIRA, Floriano J. G. de (orgs.). Metrópole: governo, sociedade e território. Rio de Janeiro: DP\&A, coleção "Espaços do desenvolvimento". 2006.

SILVA, Luiz S. D. da (org.). Relações cidade-campo: fronteiras. Goiânia: Editora da UFG. 2000.

Adão Francisco de Oliveira - Professor da UNITINS e doutorando em Dinâmica Socioespacial / Geografia pelo IESA/UFG. Pesquisador do Observatório das Metrópoles - Núcleo Goiânia.

Eguimar Felício Chaveiro - Coordenador do Programa de Pós-Graduação em Geografia do IESA/UFG. Pesquisador do Observatório das Metrópoles - Núcleo Goiânia. 